\title{
Relações intertextuais entre As Bacantes de Eurípides e Senhora dos Afogados de Nelson Rodrigues
}

\author{
Vania Maria Moragas Ferreira \\ E. E. Machado de Assis \\ vaniamoragas@yahoo.com.br
}

\begin{abstract}
This article's focus consists on the study of Two tragedies: Euripides' Bacchae and Nelson Rodrigues' Senhora dos Afogados. Despite the long period which separate these two works and authors, one will notice that there are similarities and analogies which can be traced between the two "tragedies", indicating that a more detailed study of them is worthwhile and can shed a new light in our understanding of them as single pieces. Throughout this work it will be discussed how Nelson Rodrigues appropriates Euripides' text in Senhora dos Afogados. We realize that the appropriation of the Greek text was done through analogies, inversions and/ or dislocations, and we see that there is not a copy of the Greeks tragic model, but, on the contrary, that there are coincidences. Nelson Rodrigues aims not to sacralize the classic model, but searches for a new reality, which causes ruptures with the tradition.

KEYWORDS: tragedy; Bacchae; Euripides; Senhora dos Afogados; Nelson Rodrigues.
\end{abstract}

Tomando como objeto de análise os textos de duas peças que fazem parte, uma dos padrões clássicos, a saber, As Bacantes de Eurípides, outra dos padrões modernos, Senhora dos Afogados, de Nelson Rodrigues, propomos uma comparação dos aspectos confluentes entre essas duas obras. Focalizaremos tanto as ações desenvolvidas por Moema, personagem central de Senhora dos Afogados, quanto aquelas desenvolvidas pelo deus Dioniso n'As Bacantes. Buscaremos, ainda, outros pontos convergentes relativos ao uso, pelo texto moderno, de formas de encenação encenação antigas.

Indispensável considerar, ao propormos uma análise dessas obras, que não estamos falando de obras idênticas e que alguns elementos que serão apontados - por exemplo, as ações das personagens nas respectivas peças - levam-nos apenas a traçar paralelos e sugerir uma certa intencionalidade do autor moderno na recuperação dos clássicos.

Já numa leitura superficial, pode-se notar que Nelson Rodrigues, o grande renovador da dramaturgia brasileira, resgata, em suas peças, o coro, as máscaras, os conflitos desencadeados no âmbito familiar, cenas de mutilação ou crimes que caracterizam a tragédia grega antiga. Essa proximidade - aspectos formais, emocionais, espetaculares e filosóficos -, trazida para o cotidiano carioca - pois o autor abre mão da linguagem nobre e solene característica apontada por Aristóteles para a tragédia ática - 
renova o interesse pelo trágico e aponta para uma reinterpretação do mesmo no que se poderia chamar de "tragicidade" brasileira. Esse é sem dúvida um dos muitos aspectos que se destaca dentro de sua obra teatral e, mais especificamente, nas suas "Tragédias cariocas" e suas "Peças míticas".

Senhora dos Afogados está situada, na edição do teatro completo de Nelson Rodrigues, organizada por Sábato Magaldi (Nova Aguilar, 1994), no bloco das "Peças míticas". Essa classificação baseia-se no conflito dentro das relações familiares que é abordado de forma recorrente, com sentimentos exacerbados, levando as personagens a praticar atos extremos. Na utilização de temas como incesto e morte - tanto a morte ocorrida no passado, quanto aquelas ocorridas no presente, rondando a família -, percebe-se uma retomada de mitos antigos e uma transformação e reconstrução (ou reinterpretação) de tais mitos, levando o espectador a identificar-se com os problemas colocados em cena e a fazer julgamentos críticos. Evidencia-se, na busca pelo sentido das coisas ou algo que justifique aquelas ações, o carâter mítico da peça, ao mesmo tempo que se percebe uma renovação geral dos mitos, trazidos para a contemporaneidade.

Dessa forma, Nelson Rodrigues revela-se, a nosso ver, um "transcriador", no sentido de que ele se coloca como quem erige uma outra obra em que se podem reconhecer traços ${ }^{1}$ de um original, criando, assim, uma literatura própria, adaptada ao contexto sócio-político e econômico brasileiro. Nestas "Peças míticas", pois nelas o autor retoma fragmentos de obras antigas, mistura personagens e enredos e modifica situações estratégias, que só podem ser vistas através da análise cuidadosa do processo da transtextualidade que se dá em suas criações. Ele também poderia ser visto como um precursor da pós-modernidade: não só por usar no teatro uma língua habitual, por descrever a marginalidade da personagem, mas também pela ruptura, transgressão e dessacralização do modelo clássico. Nelson Rodrigues afirmou ser um autor "desagradável". Contudo, seu teatro é amplamente encenado e aplaudido em todo o Brasil, mesmo escandalizando através do desejo de mexer com a passividade e com os

\footnotetext{
${ }^{1}$ Entendemos por isso marcas distintivas de um gênero, estilo ou autor. Trajano Vieira, por exemplo, nomeia "traço marcante do idioma épico a estrutura formular do poema homérico" (cf. Vieira, T. Entre Joyce e Odorico. A "Ilíada" de Haroldo de Campos. In: de Campos, Haroldo; Mendes, O. Os nomes e os navios. São Paulo: Sette Letras, 1999, p. 7).
} 
valores tradicionais muito presentes em nossa cultura, firmada na dicotomia do bem e do mal e numa moral religiosa conservadora. ${ }^{2}$

$\mathrm{Na}$ tentativa de entender o gênero trágico, sem outra teoria antiga sistematizada, sempre nos reportamos a Aristóteles. ${ }^{3}$ Há quem negue a existência de tal gênero no mundo moderno, pois a luta do herói trágico contra forças poderosas, originalmente ligadas ao arbítrio divino, teria sido substituída hoje em dia. A nova tragédia, segundo alguns, ${ }^{4}$ procurara deslocar a fatalidade para o conflito com o meio sufocante ou a própria falha interior. Mas Nelson Rodrigues está atento para o toque trágico, a mistura equilibrada entre o riso e o pranto é frequente em seu teatro...

Senhora dos Afogados é a quinta peça de Nelson Rodrigues e foi escrita numa época em que o autor buscava tratar de temas míticos em suas peças. Denominada tragédia pelo próprio autor, tem três atos e seis quadros e foi escrita em 1947. Censurada e interditada pela justiça, a peça só foi liberada em 1953.

Sua primeira encenação foi marcada por um místo de aplausos e vaias. Uma parte do teatro o considerava "gênio" e outra parte "tarado". Tanta polêmica se deve ao teor de uma obra que trata de incestos, crimes, paixões fulminantes e outros "abscessos" que a sociedade sempre fez questão de esconder. Desta vez, porém, a reação foi pior do que o esperado, e marcou Nelson Rodrigues para sempre. Ele chegou a dizer, no camarim, depois da fatídica estreia desta peça: “A estrela está no céu. Quem não vê, não vê. Mas ela brilha do mesmo jeito". 5

A ação se inicia no dia da morte por afogamento de Clarinha, uma das filhas de Misael Drumond. Um coro pranteia, ao contrário do que se espera, não a morte de Clarinha, mas a de uma prostituta que fora assassinada há dezenove anos. Essas rezas e lamentações invadem o espaço da casa dos Drumond e se misturam às rezas da família.

\footnotetext{
2 Nelson Rodrigues concedeu uma entrevista à revista Dionysos em 1940 (cf. Castro, R. $O$ anjo pornográfico. São Paulo: Cia. das Letras, 1994, p. 213) e disse que, a partir de Álbum de família, tinha enveredado por um caminho que poderia levá-lo a qualquer destino, menos ao êxito. Esse caminho era o de um teatro "desagradável", com peças chocantes, porque eram obras fétidas, pestilentas, capazes de produzir "tifo" e "malária" na plateia.

${ }^{3}$ Cf. Poética 1449 b 24: É, pois, a tragédia como imitação de uma ação de caráter elevado, completa e de certa extensão, em linguagem ornamentada e com as árias espécies de ornamentos distribuídas pelas diversas partes [do drama], [imitação que se efetua] não por narrativa, mas mediante atores, e que, suscitando o terror e a piedade, tem por efeito a purificação dessas emoções (tradução de Eudoro de Sousa).

${ }^{4}$ Moreno, C. A. C. Catarse brasileira. Por uma leitura da tragédia, p. 1 - acesso em 25 de agosto de 2006 - <http://www.eco.ufrj.br/semiosfera/anteriores/semiosfera02/perfil/mat2/txtmat $2 . h t m>$.

${ }^{5}$ Cf. Castro, op. cit., p. 254.
} 
Misael é o suspeito daquele assassinato ocorrido no dia de seu casamento com D. Eduarda. O enredo se desenrola em torno dessas mortes e do mistério que as cerca.

A presença do coro é um aspecto significativo de Senhora dos Afogados. Nessa peça, o coro, representado por vizinhos, adquire grande importância, acumulando múltiplas funções: em primeiro lugar, ele instaura o coletivo na cena e, dessa forma, faz comentários triviais, usa lugares-comuns, repassa informações importantes à plateia e carrega o cenário. Em determinadas cenas, o coro, nos moldes clássicos, conversa com as personagens e até mesmo procura mostrar o que está certo ou errado, como, por exemplo, quando tenta mostrar a Moema que seu noivo não tem boa fama e, por isso, ela deve romper o noivado: "Moema (implacável) - Quero que digas - por que devo desmanchar o casamento?"

A partir daí D. Eduarda passa a perguntar ao coro de vizinhos a respeito do noivo de Moema: ${ }^{7}$

D. Eduarda - Você conhece todas as infâmias. Que faz o noivo de minha filha?

Vizinho - Passa o dia com três ou quatro mulheres...

Vizinho (exultante) - Da vida.

Vizinho - Mulheres da vida.

D. Eduarda (eufórica) - Ouviste?

Moema (inescrutável) - Continua.

Vizinho - Sempre bêbado.

D. Eduarda - E o corpo? Que tem ele no corpo?

Vizinho - Nomes de prostitutas... No peito, nas costas, em todo o corpo, nome de vagabundas que ele conheceu...

D. Eduarda - O que é que ele diz para todo o mundo ouvir?

Vizinho - Diz que talvez se case, mas só com uma mulher da vida. Só acha graça nesse tipo de mulher.

Voltando ao enredo da peça, vemos que quem matou a prostituta há dezenove anos foi mesmo Misael Drumond e que Moema afogou não só Clarinha, mas também sua outra irmã, Dora, no intuito de se tornar a única filha. Moema, uma mulher forte, manipuladora e apaixonada pelo pai, odeia sua mãe, que é seu principal alvo. Vale notar que alguns comparam essa personagem rodrigueana com Electra, mas ela não precisa de um irmão para ajudá-la a alcançar seus objetivos, nem tampouco quer vingar-se de uma mãe cruel, ou chora a morte de um pai. Ela instiga o pai a matar D.

\footnotetext{
${ }^{6}$ Cf. Rodrigues, N. Senhora dos Afogados. In: prefácio de Sábato Magaldi. Rio de Janeiro: Nova Aguilar, 1994, p. 678.

${ }^{7}$ Cf. Rodrigues, op. cit., p. 679. Teatro completo. Organização geral e
} 
Eduarda, sua mãe, acusando-a de adultério, pois esta foge com o noivo de Moema que era, na verdade, o filho de Misael com a prostituta assassinada. Não obstante, procura também afastar as outras mulheres da família - mesmo que para isso tenha de matá-las -, sempre com o objetivo de ter o pai só para si. Embora nutra esse amor incestuoso pelo pai e, por isso, proibido, ela é rejeitada por ele. Percebemos a complexidade da construção mítica no texto de Nelson Rodrigues, algo que poderíamos postular como fragmentos de Édipos enviesados. Numa revitalização de mitos gregos, o autor cria uma filha como rival da mãe e um noivo que conscientemente se aproxima da própria irmã, na tentativa de vingar a morte de sua mãe. Assim como no mito de Fedra e de seu enteado Hipólito (v. 352-359) $)^{8}$ surge uma atração da senhora por aquele que seria, ao fim, um enteado não oficial, talvez por perceber nele traços do marido quando jovem. Não podemos, também, deixar de mencionar o sentimento de Paulo pela mãe, D. Eduarda. Dessa forma, podemos apontar, numa única obra, a recuperação de vários mitos.

Ângela Leite Lopes, ao comentar a respeito da obra rodrigueana, aponta: “Temos aqui um aspecto importante. O universo de Nelson Rodrigues é povoado de incestos. O que não deixa de remeter ao universo das tragédias gregas". "E, acrescentamos, a um universo mais amplo, o mítico. Já Pereira, ${ }^{10}$ ao comentar as peças de Nelson Rodrigues, aponta que, a partir das "Peças míticas", evidencia-se o propósito do dramaturgo: elaborar situações e personagens universais, movidas pelas paixões mais primárias e essenciais do ser humano, o que explica a frequência das relações incestuosas, como a repercutir a perspectiva, ainda revolucionária e inovadora no Brasil dos anos quarenta, de que a origem e fim de todo desejo humano se situavam na triangulação edípica. Daí alguns críticos atribuírem às personagens rodrigueanas um caráter edipiano.

Entretanto, há, entre a personagem de Nelson Rodrigues e Édipo, uma perversidade maior na de Rodrigues, uma vez que Édipo desconhecia suas origens e, por isso, todas as suas ações se davam por pura ignorância de si próprio. Toda a sua vida foi marcada pela ambiguidade. Decifrador de enigmas, ele vive na escuridão,

\footnotetext{
${ }^{8}$ Em Eurípides, a deusa Afrodite provoca em Fedra a paixão por Hipólito, cf. v. 352-359.

${ }^{9}$ Lopes, A. L. Nelson Rodrigues. O trágico e a cena do estilhaçamento. Travessia. Revista de literatura brasileira. Florianópolis, n. 28, p. 86, 1994.

${ }^{10}$ Pereira, V. H. A. Nelson Rodrigues e a obscena contemporânea. Rio de Janeiro: UERJ, 1999. p. 117.
} 
primeiro pela ignorância de seu passado e, posteriormente, já sabendo quem era na verdade, torna-se cego pelas próprias mãos.

As personagens de Nelson Rodrigues, muito embora nutram sentimentos incestuosos, não desconhecem suas origens. Elas sabem muito bem quem são, conhecem seus familiares e, mesmo assim, desejam este tipo de relação, vivendo numa situação limite e agindo sempre com o intuito de obter êxito nesse caminho de satisfação pessoal. Para elas, “o incesto é a única lei que conhecem, já que nem para o amor nem para o ódio conseguem sair de si mesmas". 11

Dessa forma, acreditamos que comparar Moema a Dioniso é desvendar um outro lado da personagem ainda pouco explorado, uma vez que ela, por assim dizer, é "construída" sob um conjunto de máscaras simbólicas, postas e sobrepostas, que não escondem, mas revelam e formam sua personalidade. Fazendo uso dessas diversas máscaras, ela impõe sua vontade, algumas vezes com docilidade, outras vezes assustando e causando terror em suas vítimas, pois realiza, no decorrer da peça, ações paradoxais, e provoca sentimentos também paradoxais. Sendo essas máscaras simbólicas, e, por isso, invisíveis, constituem-se mais perigosas, elas não podem ser vistas, só pressentidas. No caso de Moema, suas vítimas só percebem a espécie de máscara utilizada pela personagem quando se veem sem saída, enleadas em sua teia, ${ }^{12}$ como fica evidente na fala de seu irmão: "Paulo - Eu te julgava fria ... Mas tenho medo de ti e de mim quando és meiga. [...]"; ${ }^{13}$ ou quando o pai chega em casa e estende os pés sobre uma pequena almofada. Neste instante "muito humilde e doce, Moema substitui as duras botinas do pai por outro calçado, mais leve e macio". ${ }^{14}$ e afirma que a partir daquele dia seria ela que sempre faria aquele carinho para o pai, já que Clarinha estava morta. Já em outras cenas, torna-se mais evidente sua maldade: "Neste momento, Paulo corre e apunhala o noivo pelas costas. O noivo se projeta pela escada. Tudo absolutamente imóvel. Paulo petrificado. Moema com seu rosto cruel”. ${ }^{15}$ E ainda, quando relata com frieza que deixou a avó morrer de inanição: "Eu lhe dava de comer e

\footnotetext{
${ }^{11}$ Cf. Prado, D. A. Nelson Rodrigues. In: Rodrigues, op. cit., p. 270-271.

12 Cf. Guimarães, M. R. Moema. Mito, monstro e máscaras. Anais do V Congresso Nacional de Linguística e Filologia, Rio de Janeiro, vol. XX, 2001, p. 4 - acesso em 27 de julho de 2006 $<$ http://www.filologia.org.br/vcnlf/anais\%20v/civ5_09.htm>.

${ }^{13}$ Cf. Rodrigues, op. cit., p. 712.

${ }^{14}$ Cf. Rodrigues, op. cit., p. 685.

${ }^{15}$ Cf. Rodrigues, op. cit., p. 720.
} 
de beber, mas há muitos dias que eu me esqueço... E pouco a pouco ela foi perdendo as forças... Hoje, de manhã, deixou de respirar..."16

Percebe-se que o jogo, as ações das personagens e a encenação marcam e encarnam o próprio Dioniso, o deus-máscara que encerra em si o conflito entre o ser e a aparência, na ambiguidade de sua forma, de sua máscara e encenação.

Dioniso, por sua vez, está n'As Bacantes com uma máscara sorridente. Ele é ao mesmo tempo deus da fertilidade agreste e deus do vinho, potencial causador de alterações da consciência. É o deus que causa prazer e dor, que é encantador, sedutor e também cruel, aterrorizante, é um misto de fascínio e rejeição, a divindade da mistura. É exaltado, como na cena em que Tirésias diz:

É que o deus não distingue se é o jovem ou o mais idoso o que deve dançar, mas da parte de todos quer receber honrarias por igual; quer ser engrandecido sem discriminar ninguém. ${ }^{17}$

É objeto de fascínio por parte de Penteu:

A verdade é que não és desgracioso de corpo(...). Os teus cabelos compridos, porque não lutas nas palestras, caem-te pelas faces, plenos de desejo. Graças aos teus cuidados, possuis uma tez branca, e com a tua beleza consegues captar as graças de Afrodite. ${ }^{18}$

O deus que se mostra arrebatador e possuidor:

Por isso eu as sacudi para fora de suas moradas, tomadas de delírio, e, do espírito enlouquecido, habitam na montanha. E forcei-as a usar o libro das minhas orgias e a toda a raça feminina dos Cádmios, a quantas mulheres havia, fi-las sair da casa, desvairadas. ${ }^{19}$

As características metamórficas do deus Dioniso são mencionadas, pelo coro, n'As Bacantes:

Aparece com a forma de touro

Ou serpente multifauce ou leão ignispirante .

Vai, Ó Baco, com teu rosto sorridente,

\footnotetext{
${ }^{16}$ Cf. Rodrigues, op. cit., p. 727.

17 Todas as traduções de As Bacantes de que nos servimos são de autoria de Maria Helena da Rocha Pereira (cf. referências finais, v. 264-265).

${ }^{18}$ Cf. As Bacantes, v. 452-459.

${ }^{19}$ Cf. As Bacantes, v. 33-36.
} 
E ao caçador das Ménades rodei-o com teu laço

Mortífero, quando ele tombar

Na manada das Bacantes. ${ }^{20}$

Comprova-se, assim, que ambas as personagens utilizam-se de máscaras visíveis ou não - para alcançar seus objetivos, e isso as faz dotadas de uma certa ambiguidade de sentimentos, um misto de terror e sedução: de outra forma não conseguiriam manipular todos os que as cercam. Outros comportamentos paradoxais presentes na obra de Nelson Rodrigues nos remetem aos rituais que antecedem o Festival em honra a Dioniso, como passaremos a demonstrar.

Para tal, voltemos ao ponto inicial de Senhora dos Afogados, quando a família Drumond, apesar de sofrer a dor da perda de Clarinha, necessita cumprir um papel social e comparece a um banquete oferecido a Misael, por ocasião de sua promoção a Ministro. Ao retornarem do banquete, a conversa flui num aparente desencontro de sensações: ${ }^{21}$

D. Eduarda (dolorosa) - Tua filha morreu, Misael.

Misael - Morreu...

D. Eduarda (com espanto) - E no mar!

Moema (doce) - Estava bonito o banquete, pai?

(Misael reassume o ar de estátua no respectivo monumento)

Misael - Primeiro Dora, depois Clarinha... E no mar, as duas! (muda de tom). O banquete estava bonito... Muito bonito (erguendo meio corpo na cadeira, e com exaltação). Senhoras decotadas!... O governador!... E até aquele padre... O governador fez um discurso...

D. Eduarda - Misael, nós só devemos falar de Clarinha. (com medo) Ela está no fundo do mar, Misael...

Moema - Fale do banquete, pai!

O que podemos perceber nessa cena é que ela se realiza num misto de sentimentos e emoções desencontradas. Fala-se de alegria e dor e experimenta-se, ao mesmo tempo, dois tipos de sentimentos. Essa relação de tristeza e alegria nos remete à inserção do gênero trágico nas festas de Dioniso. Paradoxalmente, uma marca de dor na alegria, a constatação de que, mesmo em festa, não nos devemos esquecer de nossas penas. $^{22}$

\footnotetext{
${ }^{20}$ Cf. As Bacantes, v. 1018-1023.

${ }^{21}$ Cf. Rodrigues, op. cit., p. 685.

${ }^{22}$ Cf. Barbosa, T. V. R. Sangue, suor e vinho. In: Lessa, F.; Bustamante, R. M. (org.). Memória e festa. Rio de Janeiro: Mauad, 2005, p. 63-71.
} 
Também nos remete aos rituais dionisíacos o cortejo que leva D. Eduarda ao "Café do Cais":

Paulo - Vi um grupo passando, ao longe, entre chamas. Homens carregando uma mulher... Pareciam ser, os vizinhos... Mas não pode ser... Eles não estariam em todos os lugares ao mesmo tempo ... E na frente do grupo ia teu noivo, nu da cintura para cima... Todos caminham como se levassem aquela mulher para um sacrifício... ${ }^{23}$

Como se fosse uma procissão, vemos retomada uma tradição de ritualística, pois, no festival de Dioniso, além da tragédia, tinham parte também sacrifícios, procissões, proclamações de honrarias e mesmo uma assembleia. ${ }^{24}$ Mas não é somente com os rituais dionisíacos que as cenas se relacionam. Da mesma forma, o texto de Senhora dos Afogados traz importantes ligações intertextuais com o texto d'As Bacantes. Tomem-se como exemplo a cena do estábulo de Penteu, quando Dioniso nos relata o sucedido no interior do palácio:

Aí mesmo esteve a afronta que lhe fiz: é que julgando que me aprisionava, nem me tocou nem me agarrou; apenas se alimentava de esperanças. Encontrou um touro no estábulo para onde me levou para me encerrar. Atirou-lhe um laço em volta dos joelhos e dos cascos, a resfolegar de fúria; do corpo gotejava-lhe o suor e mordia os lábios. E eu, presente a pouca distância, estava sentado e tranquilo, a olhar. ${ }^{25}$

Esta cena em nossa opinião merece atenção pelo fato de Dioniso estar sentado assistindo ao que se passava, sem interferir, a olhar calmamente. Curiosamente, temos uma cena em Senhora dos Afogados que nos lembra a cena citada d' As Bacantes, por também apresentar uma situação em que alguém - o vendedor de pente - assiste passivamente a uma cena agitada:

Misael - Não sou assassino da esposa... Tu, vendedor de pentes, que foste testemunha de tudo...

(novo tom) Quando agarrei minha mulher pelos cabelos...

Vendedor de pentes (informativo) - Foi; eu estava lá e vi.

Misael - Viram? Quando cheguei na praia, tu ficaste de longe, espiando...

Vendedor de pentes - Só espiando. Eu sabia que tu ias matar tua esposa.

\footnotetext{
${ }^{23}$ Cf. Rodrigues, op. cit., p. 711.

${ }^{24}$ Barbosa, T. V. R. Sangue, suor e vinho, op. cit., p.64.

${ }^{25}$ Cf. As Bacantes, v. 616-620.
} 
Misael (gritando) - Mas eu não a matei! Só matei as mãos!

Vendedor de pentes - Me enganei, doutor... Pensei uma coisa e aconteceu outra... ${ }^{26}$

Essa passagem destaca-se pela proximidade da cena d'As Bacantes, e há, além da inércia do vendedor de pentes que assiste à cena, a ironia presente na palavra “espiando"; ele estava "só espiando".

Parece-nos, porém, que, na peça de Nelson Rodrigues, a direção de leitura dessa cena seja diferente da leitura metateatral ${ }^{27}$ proposta pelos teóricos para a peça de Eurípides. Isso porquê, embora a personagem estivesse passivamente assistindo a uma cena, não é explicitado que estivesse sentada a olhar tranquilamente. Sua posição parece mais uma situação de espreita, de testemunha ocular de um crime, e em momento algum é atribuída ao vendedor de pentes uma postura de espectador, como acontece com Dioniso n'As Bacantes.

Ainda, dentre muitos pontos que poderiam ser apontados como confluentes nas duas obras, destacamos a mutilação das personagens Penteu e D. Eduarda. A personagem sofre o dilaceramento corporal e também moral e o espectador sente, diante desse tipo de cena, um misto de piedade e horror. Para Barbosa, "aí está a grandeza maior de uma tragédia: na forma através da qual o poeta une intimamente movimentos conflitantes. Isso é próprio do ritual díonisíaco materializado na cena", ${ }^{28}$

Penteu, n'As Bacantess, é punido por se recusar a venerar Dioniso e tem seu corpo dilacerado: "Levava uma o braço, outra um pé ainda calçado. Desnudavam-se as costelas, dilaceradas pelas unhas". ${ }^{29}$

Em Senhora dos afogados, temos uma situação de mutilação das mãos de D. Eduarda. Moema tem as mãos parecidas com as mãos de sua mãe, porém não gosta desse aspecto que une mãe e filha; uma vez que tem sua mãe como rival, quer livrar-se dessa semelhança, acreditando que, dessa forma, seria única. Reage agressivamente quando o assunto é a semelhança entre as duas: ${ }^{30}$

\footnotetext{
${ }^{26}$ Cf. Rodrigues, op. cit., p. 723.

${ }^{27}$ Para uma análise mais cuidadosa dessa passagem d'As Bacantes, remeto o leitor aos textos Euripides. Bacchae. Introduction and commentary by E. R. Dodds. Oxford: Clarendon Press, 1960, p. 154; Euripide. Les Bacchantes. Commentées par J. Rooux. Paris: Les Belles Lettres, 1972, p. 447; e ao artigo supracitado de Barbosa, p. 63-71.

${ }^{28}$ Cf. Barbosa, T. V. R. A construção do horror na tragédia grega. In José Luís Jobim... et alii (org.): Anais do "X Congresso Internacional da Abralic". Rio de Janeiro: Abralic, 2006. Vol. I, n. 1, p. 1-4.

${ }^{29}$ Cf. As Bacantes, v. 1135.

${ }^{30}$ Cf. Rodrigues, op. cit., p. 682.
} 
Paulo - Vocês são parecidas como duas chamas.

Moema - É mentira! Eu e ela não somos uma mesma pessoa... Só as nossas mãos são parecidas! Se parecem tanto, tanto! Não queria ter essas mãos, não queria que elas fossem minhas... [...] São elas que me ligam à minha mãe... Enquanto elas existirem, serei filha de sua carne...

$\mathrm{O}$ adultério de D. Eduarda justificaria e poderia resultar em sua morte, mas, diante da possibilidade de castigar D. Eduarda pelo adultério, Moema tem uma ideia que é, para ela, a oportunidade de se livrar da parte que a une à sua mãe, as mãos:

[...] Moema (mais feroz) - Neste momento tua mulher está com outro...

Misael (com um princípio de ódio) - E acariciando o corpo de outro, com estas mãos...

(Toma as mãos da filha e examina-as)

Moema (para si mesma) - As mãos...

(Espanto de Moema que tem uma ideia e se agarra a ela, desesperadamente)

Moema (fora de si) - E por que não castiga as mãos? (num crescendo) As mãos são mais culpadas no amor... Pecam mais... Acariciam... O seio é passivo; a boca apenas se deixa beijar... $\mathrm{O}$ ventre apenas se abandona... Mas as mãos, não... São quentes e macias... E rápidas... $\mathrm{E}$ sensíveis... Correm no corpo...

Misael (fora de si) - As mãos! ${ }^{31}$

Interessa pensarmos que o castigo físico é a forma encontrada, nas duas peças, de punição para a culpabilidade. No caso de D. Eduarda, cortar as mãos representa cortar a culpa. As cenas em questão geram compaixão. Nesse sentido, Barbosa, ao citar Aristóteles, afirma que:

A compaixão, nos termos de Aristóteles, é também, como o phóbos, uma dor (lýpe) por um mal que se mostra assolador ou doloroso e que atinge a quem não o merece. A compaixão surge quando um mal iminente se aproxima de um parente ou de um nosso semelhante e temos ainda controle de nossa capacidade para perceber o sofrimento que poderá advir. Tudo o que é penoso e destrutivo é digno de compaixão: os ultrajes corporais, os maus-tratos, a velhice, as doenças, a falta de alimento, a má fortuna, a fealdade, a debilidade, a mutilação. $^{32}$

${ }^{31}$ Cf. Rodrigues, op. cit., p. 710.

${ }^{32}$ Cf. Barbosa, op. cit., 2006, p. 4. 
Diante de cenas como essas, somos levados a várias sensações: não somente compaixão e horror, mas também nos sentimos incomodados, perplexos diante de tanta crueldade. Contudo, sabemos que essas emoções suscitadas pela tragédia certamente nos levarão à kátharsis.

Nelson Rodrigues acreditava na necessidade da kátharsis, para ele "a ficção, para ser purificadora precisa ser atroz. A personagem é vil para que não o sejamos. Ela realiza a miséria inconfessa de todos nós". 33

\section{Conclusão}

A abordagem comparativa, que norteou o presente estudo, evidenciou aspectos confluentes do mito grego n'As Bacantes, de Eurípides e da tragédia brasileira Senhora dos Afogados, de Nelson Rodrigues. Não há “cópia” do modelo trágico grego, há coincidências; assim, percebemos em Nelson Rodrigues a dessacralização do modelo clássico, apontando para uma nova realidade, que busca uma quebra com a tradição. Notamos que o clássico persiste quando encontra um contexto social que o autor julga propício para ser revivido, entretanto, sem a existência do plano divino, somente humano. A relação da contemporaneidade com a tragédia está na utilização do clássico como referência para criar sua própria tragédia: importar o mito e contextualizá-lo na atualidade, apontando para uma "tragédia grega brasileira".

\section{Referências}

ARISTÓTELES. Poética. Tradução de Eudoro de Souza. Lisboa: Imprensa Nacional/ Casa da Moeda, 1986.

ARROJO, R. A tradução como paradigma dos intercâmbios intralinguísticos. In: _. Tradução, desconstrução e psicanálise. Rio de Janeiro: Imago, 1993, p.51-69.

BARBOSA, T. V. R. Sangue, suor e vinho. In: LESSA, F.; BUSTAMANTE, R. M. (org.). Memória e festa. Rio de Janeiro: Mauad, 2005, p. 63-71.

. A construção do horror na tragédia grega. In: José Luís Jobim... et alii. (org.) Anais do "X Congresso Internacional da Abralic". Rio de Janeiro: Abralic, 2006. Vol. I, n. 1, p. 1-8.

${ }^{33}$ Cf. Rodrigues, N. Flor de Obsessão. As 1000 melhores frases de Nelson Rodrigues. Seleção e organização de Ruy Castro. São Paulo. Cia. das Letras. 2002, p. 161. 
de CAMPOS, H. Da transcriação. Poética e semiótica da operação tradutora. In: . Metalinguagem e outras metas. São Paulo: Perspectiva , 1992.

. Transluciferação mefistofáustica. In: Deus e o diabo no

Fausto de Goethe. São Paulo: Perspectiva, 1980, p.179-209.

CASTRO, R. O Anjo pornográfico. A vida de Nelson Rodrigues. São Paulo: Cia. das Letras, 1992.

EURIPIDES. Bacantes. Tradução de M. H. da Rocha Pereira. Lisboa: Edições 70, 1992.

. Bacchae. Introduction and commentary by E. R. Dodds. Oxford: Clarendon Press, 1960.

. Les Bacchantes. Commentée par J. Rooux. Paris: Les Belles Lettres, 1972.

EURÍPIDES; SÊNECA; RACINE. Hipólito e Fedra. Três Tragédias. Tradução, estudo introdutório e notas de Joaquim Brasil Fontes Jr. São Paulo: Iluminuras, 2007.

GENETTE, G. Palimpsestes. La littérature au second degré. Paris: Seuil, 1982.

GUIMARÃES, M. R. Moema. Mito, monstro e máscaras. Anais do V Congresso Nacional de Linguística e Filologia, Rio de Janeiro, vol. XX, 2001 - acesso em 27 de julho de $2006<$ http://www.filologia.org.br/vcnlf/anais\%20v/civ5_09.htm>.

LESKY, A. A tragédia grega. São Paulo: Perspectiva, 2001.

LOPES, A. Nelson Rodrigues. Trágico, então moderno. Rio de Janeiro: UFRJ/ Tempo Brasileiro, 1992.

Nelson Rodrigues. O trágico e a cena do estilhaçamento. Travessia. Revista de literatura brasileira. Florianópolis, n. 28, 1994, p. 67-87.

MORENO, C. A. C. Catarse brasileira. Por uma leitura da tragédia - acesso em 25/ $08 /$ 2006

<http://www.eco.ufrj.br/semiosfera/anteriores/semiosfera02/perfil/mat2/txtmat2.htm>. 
PEREIRA, V. H. A. Nelson Rodrigues e a obscena contemporânea. Rio de Janeiro: UERJ, 1999.

PONTARA, C. Senhora dos Afogados - acesso em 04 de agosto de 2006. $<$ http://www.celsopontara.com.br/teatro/sala04.html>.

PRADO, D. A. Nelson Rodrigues. In: RODRIGUES, N. Teatro completo. Organização geral e prefácio de Sábato Magaldi. Rio de Janeiro: Nova Aguilar, 1994, p. 270-271.

RODRIGUES, N. Senhora dos Afogados. In: RODRIGUES, N. Teatro completo. Organização geral e prefácio de Sábato Magaldi. Rio de Janeiro: Nova Aguilar, 1994.

RODRIGUES, N. Flor de Obsessão. As 1000 melhores frases de Nelson Rodrigues. Seleção e organização de Ruy Castro. São Paulo: Cia das Letras, 2002.

VIEIRA, T. Entre Joyce e Odorico. A "Ilíada" de Haroldo de Campos. In: de Campos, Haroldo; Mendes, O. Os nomes e os navios. São Paulo: Sette Letras, 1999, p. 7-13.

WILAMOWITZ-MOELLENDORFF, U. Qu'est-ce qu'une tragédie attique? Paris: Les Belles Lettres, 2001. 